\title{
Properties and Structural Studies of Multi-Wall Carbon Nanotubes-Phosphate Ester Hybrids
}

\author{
Marina Massaro $^{1}$, Serena Riela ${ }^{{ }^{*}}$, Giuseppe Cavallaro ${ }^{2}$, Maria Luisa Saladino ${ }^{1}$, \\ Simonpietro Agnello ${ }^{2}$, Renato Noto ${ }^{*}$ \\ ${ }^{1}$ Dipartimento STEBICEF, Sezione di Chimica, Università degli Studi di Palermo, \\ Palermo, Italy \\ ${ }^{2}$ Dipartimento di Chimica e Fisica, Università degli Studi di Palermo, \\ Palermo, Italy \\ Email: *serena.riela@unipa.it
}

Received January 20, 2013; revised March 7, 2013; accepted April 10, 2013

Copyright (C) 2013 Marina Massaro et al. This is an open access article distributed under the Creative Commons Attribution License, which permits unrestricted use, distribution, and reproduction in any medium, provided the original work is properly cited.

\begin{abstract}
Long chain phosphate esters bearing at least one or two aryl groups have been synthesized and used for the preparation of stable multi-walled carbon nanotube (MWCNT) hybrids. The non-covalent interaction ester/MWCNT has been investigated by several techniques (SEM, UV-vis, ${ }^{31} \mathrm{P}-\mathrm{NMR}, \mathrm{RAMAN}$ ). The used phosphate ester derivatives demonstrated the ability to produce an excellent dispersion of MWCNT in $\mathrm{CHCl}_{3}$. The obtained dispersions showed a great stability from one to at least three weeks in the range of concentration considered. Thermal analysis showed an increase in the decomposition temperature for the hybrids with respect to pristine MWCNT.
\end{abstract}

Keywords: Multi-Wall Carbon Nanotubes Hybrids; Non Covalent Functionalization; Phosphate Esters

\section{Introduction}

Since their discovery in 1991 [1], single (SW) or multi walled (MW) carbon nanotubes (CNT) have attracted a lot of attention owing to their unique physical, chemical, and mechanical properties [2]. CNT are expected to find applications in several technological contexts [2], e.g., as in field emission displays, supercapacitors, and molecular computers. CNT are primarily employed in material science [3] as well as reinforcing agents dispersed in a continuous matrix polymer [4]. As a matter of fact compared to the resin base, polymers reinforced with very low percentages of nanoparticles (about $2 \%$ - 5\%) present even dramatic improvements in thermo-mechanical properties, barrier properties and fire resistance. CNT may also surpass traditional fillers and fibers (e.g. glass, mineral fillers, calcium carbonate, graphite, metal oxides, carbon black) in heat resistance, dimensional stability and electrical conductivity. The thermal and electrical conductivities of PVC, one of most widely used plastic material, are remarkable modified for adding of MWCNT amounts [5]. Unfortunately, CNT occur in form of aggregated and parallel bundles, as a result of substantial van der Waals interactions [6], which make

${ }^{*}$ Corresponding authors. them unsatisfactorily dispersible or soluble in most common solvents [7]. This constitutes a crucial drawback in their processing. Thus, a number of different approaches have been explored in order to disperse CNT in both aqueous and organic media. These approaches can be, in principle, divided in two categories, i.e. covalent [7-9] and non covalent [10-17] functionalization of the CNT sidewalls. Covalent functionalization involves the formation of new chemical bonds. A convenient method is to convert the CNT sidewalls to nanotube-bound carboxylic acids by means of oxidative degradation $[8,9]$. Carboxylic acid functionalized CNT can be subjected, for instance, to further chemical modification by amide or ester formation. Recently, Mikhabela et al. proposed the covalent functionalization of the CNT sidewalls by phosphorylation [18]. The phosphorilated MWCNT, obtained by a 1,3-cycloaddition reaction between diphenyl phosphoryl azide and the double bonds of the MWCNT, showed a greater thermal stability than the pristine material. The incorporation of either the pristine or the phosphorilated MWCNT into PVC polymer matrix enhanced its thermal properties, with the phosporilated MWCNT showing a larger improvement. The covalent functionalization of CNT involves a change of carbon hybridization from $\mathrm{sp}^{2}$ to $\mathrm{sp}^{3}$, sometimes leading to a possible 
partial loss of conjugation which results in decreased electron-acceptor and/or electron-transport properties. For this reason, sometimes, the non-covalent functionalization is preferable, to the covalent ones. Non-covalent functionalization involves van der Waals and $\pi-\pi$ interactions and requires the physical adsorption of suitably structured molecules onto the CNT sidewalls preserving the structural integrity of the nanotube and consequently its intrinsic electronic properties. This may be achieved by polymer wrapping, adsorption of surfactants or small aromatic molecules, or interaction with porphyrins or other biomolecules, such as DNA and peptides. Stoddart et al. described the fabrication of SWCNT/field-effect transistor devices by using hybrid SWCNT/pyrenecyclodextrin materials which can serve as chemical sensors to selectively detect nonfluorescent organic molecules, owing to the molecular recognition abilities of the cyclodextrin torus [14]. In this work we describe, by a non-covalent approach, the preparation of hybrids constituted by MWCNT and long chain phosphate esters bearing at least one or two aryl groups (Figure 1). These additives were chosen in order to profit of the beneficial effects that phosphorilation provides to MWCNT physico-chemical stability [18], without affecting their chemical structure and in order to exploit of the proximity of $\mathrm{P}-\mathrm{O}$ and $\mathrm{P}=\mathrm{O}$ bonds, present in additives, on the MWCNT surface, that could also modify their thermal conductivity. The obtained hybrids might be profitably applied as a reinforcing agent for polymeric matrix [3-5]. Recently, in fact, to improve the property of CNT, a new method of functionalization by doping CNT with inorganic atoms has been also developed [19,20]. It is known that phosphorus is a doping element which modifies the structure and properties of CNT. The experimental results showed that P-doping changes the optical transition absorptions and thermal conductivity of CNT [19]. Sun et al. developed the synthesis and characterization of P-N doped MWCNT using a floating catalyst chemical vapor deposition method. They observed that, though small, a contribution to the CNT property came of also by oxidized phosphorus present on their surface. Indeed, during the process, the presence of oxygen, adsorbed on the surface of the substrate [20], oxided the phosphorus in $\mathrm{P}-\mathrm{O}$ and $\mathrm{P}=\mathrm{O}$ forms.

\section{Experimental}

\subsection{Materials and Instrumentations}

All reagents needed were used as purchased (Aldrich), without further purification. MWCNT were provided by Prof. Mazzocchia of Politecnico di Milano, Italy. Nuclear Magnetic Resonance (NMR) spectra were recorded on a Bruker AC-E Series 300 spectrometer. The UV-vis absorbance spectra were recorded with a Beckmann DU

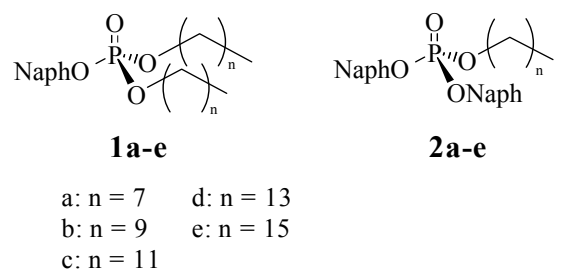

Figure 1. Structures of phosphate ester derivatives.

650 spectrometer. IR spectra were recorded with a PerkinElmer mod. 297 spectrometer.

Fluorescence spectra were acquired with a JASCO FP-777W spectrofluorimeter; the slit widths were fixed at 3 and $5 \mathrm{~nm}$ for the excitation and the emission, respectively, the excitation wavelength was fixed at 337 $\mathrm{nm}$ and emission interval was fixed at $360-450 \mathrm{~nm}$. SEM investigations were performed by using a Philips XL30 equipped with an Energy Dispersive X-ray device. Samples were supported on the stubs by carbon paint. The accelerating voltage ranged between 20 and $25 \mathrm{kV}$. Thermogravimetric analyses were performed by a Q5000 IR apparatus (TA Instruments) under a nitrogen flow of $25 \mathrm{~cm}^{3} \cdot \mathrm{min}^{-1}$ for the sample and $10 \mathrm{~cm}^{3} \cdot \mathrm{min}^{-1}$ for the balance. The weight of each sample was ca. $10 \mathrm{mg}$. The measurements were carried out by heating the sample from room temperature to $900^{\circ} \mathrm{C}$ at a rate of $10^{\circ} \mathrm{C} \cdot \mathrm{min}^{-1}$.

Micro-Raman spectra were carried out at room temperature by a Bruker-Senterra micro-Raman equipped with a $532 \mathrm{~nm}$ diode laser excitation with $20 \mathrm{~mW}$ power. Measurements were carried out in the range $3500-1000$ $\mathrm{cm}^{-1}$ with spectral resolution from 9 to $15 \mathrm{~cm}^{-1}$. The dispersions were analysed after removing of the solvent.

\subsection{Synthesis of Compounds 1,2 a-e}

The proper alkyl alcohol $(10 \mathrm{~g})$ was dissolved in $\mathrm{Et}_{2} \mathrm{O}$ $(100 \mathrm{~mL})$, under inert atmosphere $(\mathrm{Ar})$, stirred for a few minutes in an ice bath, and a suitable amount of $\mathrm{POCl}_{3}$ was added. After two days the crude compound was added dropwise, at $0^{\circ} \mathrm{C}$, to a solution of $\beta$-naphthol and $\mathrm{NaH}$ (molar ratio 1:1) in $\mathrm{Et}_{2} \mathrm{O}(500 \mathrm{~mL})$ under inert atmosphere (Ar). The mixture was stirred for 1 day, and subsequently extracted with water, then with $\mathrm{NaOH}(0.2$ $\mathrm{N}$ ) and finally with a saturated $\mathrm{NaCl}$ solution. The organic phase was dried on $\mathrm{MgSO}_{4}$, filtered and evaporated in vacuum. The residue was purified by chromatography on silica gel (eluents: petroleum ether $100 \%$, ethyl acetate $100 \%)$.

Compound 1a: red oil, yield 58\%; ${ }^{1} \mathrm{H}$ NMR (300 $\left.\mathrm{MHz}, \mathrm{CDCl}_{3}, \delta\right): 7.80(\mathrm{~m}, 3 \mathrm{H}, \mathrm{Ar} \mathrm{H}), 7.68(\mathrm{~m}, 1 \mathrm{H}, \mathrm{Ar} \mathrm{H})$, $7.42(\mathrm{~m}, 3 \mathrm{H}, \mathrm{Ar} \mathrm{H}), 4.16\left(\mathrm{~m}, 4 \mathrm{H}, \mathrm{O}-\mathrm{CH}_{2}\right), 1.68\left(\mathrm{~m}, \mathrm{CH}_{2}\right.$, $4 \mathrm{H}), 1.27\left(\mathrm{~m}, 20 \mathrm{H}, \mathrm{CH}_{2}\right), 0.88\left(\mathrm{t}, J=6.4 \mathrm{~Hz}, 6 \mathrm{H}, \mathrm{CH}_{3}\right)$ ppm. ${ }^{13} \mathrm{C}$ NMR (300 MHz, $\left.\mathrm{CDCl}_{3}, \delta\right): 148.87,134.29$, $131.26,130.16,128.07,127.05,125.79,120.49,116.79$, $69.10,32.12,30.68,29.53,25.80,23.00,14.56 \mathrm{ppm}$. IR 
(oil): $v=1286$ (s, $\mathrm{P}=\mathrm{O}), 1246$ (w, P-O-Ar), 1022 (s, P-O- $\left.\mathrm{CH}_{2}\right) \mathrm{cm}^{-1}$. Anal. calcd. for $\mathrm{C}_{26} \mathrm{H}_{41} \mathrm{O}_{4} \mathrm{P}: \mathrm{C}, 69.62 ; \mathrm{H}$, 9.21; P, 6.90. Found: C, 69.66; H, 9.19; P, 6.93.

Compound 1b: red oil, yield $78 \%$; ${ }^{1} \mathrm{H}$ NMR (300 $\left.\mathrm{MHz}, \mathrm{CDCl}_{3}, \delta\right): 7.49$ (m, 3H, Ar H), $7.44(\mathrm{~m}, 1 \mathrm{H}, \mathrm{Ar} \mathrm{H})$, 7.37 (m, 3H, Ar H), 4.17 (m, 4H, O- $\mathrm{CH}_{2}$ ), 1.70 (quintet, $\left.J=6.6 \mathrm{~Hz}, 4 \mathrm{H}, \mathrm{CH}_{2}\right), 1.31\left(\mathrm{~m}, 28 \mathrm{H}, \mathrm{CH}_{2}\right), 0.88(\mathrm{t}, J=$ $\left.6.6 \mathrm{~Hz}, 6 \mathrm{H}, \mathrm{CH}_{3}\right)$ ppm. ${ }^{13} \mathrm{C}$ NMR $\left(300 \mathrm{MHz}, \mathrm{CDCl}_{3}, \delta\right)$ : $146.99,132.41,129.39,128.30,126.20,125.19,123.93$, $118.62,114.93,67.25,30.40,28.82,28.02,27.82,27.63$, 23.94, 21.20, 12.64 ppm. IR (oil): $v=1288$ (s, $\mathrm{P}=\mathrm{O}$ ), 1245 (s, O-Ar), 1020 (s, P-O- $\mathrm{CH}_{2}$ ) cm ${ }^{-1}$. Anal calcd. for $\mathrm{C}_{30} \mathrm{H}_{49} \mathrm{O}_{4} \mathrm{P}: \mathrm{C}, 71.40 ; \mathrm{H}, 9.79 ; \mathrm{P}, 6.14$. Found: $\mathrm{C}, 71.45 ; \mathrm{H}$, 9.81; P, 6.12 .

Compound 1c: red oil, yield $74 \% ;{ }^{1} \mathrm{H}$ NMR (300 $\left.\mathrm{MHz}, \mathrm{CDCl}_{3}, \delta\right): 7.81(\mathrm{~m}, 3 \mathrm{H}, \mathrm{Ar} \mathrm{H}), 7.69(\mathrm{~m}, 1 \mathrm{H}, \mathrm{Ar} \mathrm{H})$, 7.38 (m, 3H, Ar H), 4.18 (m, 4H, O-CH $)_{2}, 1.70$ (quintet, $\left.J=6.7 \mathrm{~Hz}, 4 \mathrm{H}, \mathrm{CH}_{2}\right), 1.25\left(\mathrm{~m}, 36 \mathrm{H}, \mathrm{CH}_{2}\right), 0.89(\mathrm{t}, J=$ $\left.6.4 \mathrm{~Hz}, 6 \mathrm{H}, \mathrm{CH}_{3}\right)$ ppm. ${ }^{13} \mathrm{C}$ NMR $\left(300 \mathrm{MHz}, \mathrm{CDCl}_{3}, \delta\right)$ : 151.18, 139.09, 133.86, 129.71, 127.63, 127.46, 126.61, $125.36,120.06,116.30,68.68,31.87,30.26,29.58,29.30$, 29.06, 25.37, 22.64, $14.06 \mathrm{ppm}$. IR (oil): $v=1287$ (s, $\mathrm{P}=\mathrm{O}$ ), 1246 (s, P-O-Ar) 1052 (s, P-O-CH cm $^{-1}$. Anal. calcd.for $\mathrm{C}_{34} \mathrm{H}_{57} \mathrm{O}_{4} \mathrm{P}: \mathrm{C}, 72.82 ; \mathrm{H}, 10.24 ; \mathrm{P}, 5.42$. Found: C, $72.79 ; \mathrm{H}, 10.27$;, 5.41 .

Compound 1d: red oil, yield $71 \%$; ${ }^{1} \mathrm{H}$ NMR (300 $\left.\mathrm{MHz}, \mathrm{CDCl}_{3}, \delta\right): 7.81(\mathrm{~m}, 3 \mathrm{H}, \mathrm{Ar} \mathrm{H}), 7.69(\mathrm{~m}, 1 \mathrm{H}, \mathrm{Ar} \mathrm{H})$, $7.42(\mathrm{~m}, 3 \mathrm{H}, \mathrm{Ar} \mathrm{H}), 4.18$ (m, 4H, O-CH$), 1.65$ (quintet, $\left.J=6.8 \mathrm{~Hz}, 4 \mathrm{H}, \mathrm{CH}_{2}\right), 1.29\left(\mathrm{~m}, 44 \mathrm{H}, \mathrm{CH}_{2}\right), 0.80(\mathrm{t}, J=$ $\left.6.4 \mathrm{~Hz}, 6 \mathrm{H}, \mathrm{CH}_{3}\right) \mathrm{ppm} .{ }^{13} \mathrm{C}$ NMR $\left(300 \mathrm{MHz}, \mathrm{CDCl}_{3}, \delta\right)$ : $152.30,130.85,129.75,127.67,127.50,126.65,125.40$, 120.02, 116.41, 68.71, 31.91, 30.29, 30.19, 29.64, 29.53, 29.34, 29.09, 25.40, 22.66, 14.09 ppm. IR (oil): $v=1281$ (s, P=O), 1246 (s, P-O-Ar), 1019 (s, P-O-CH cm $^{-1}$. Anal. calcd. for $\mathrm{C}_{38} \mathrm{H}_{65} \mathrm{O}_{4} \mathrm{P}: \mathrm{C}, 73.98 ; \mathrm{H}, 10.62 ; \mathrm{P}, 5.02$. Found: C, 73.95; H, 10.65; P, 5.00 .

Compound 1e: red oil, yield $94 \%$; ${ }^{1} \mathrm{H}$ NMR (300 $\left.\mathrm{MHz}, \mathrm{CDCl}_{3}, \delta\right): 7.81$ (m, 3H, ArH), 7.69 (m, 1H, $\left.\mathrm{ArH}\right)$, $7.45(\mathrm{~m}, 3 \mathrm{H}, \mathrm{ArH}), 4.16\left(\mathrm{~m}, 4 \mathrm{H}, \mathrm{O}-\mathrm{CH}_{2}\right), 1.70(\mathrm{~m}, 4 \mathrm{H}$, $\left.\mathrm{CH}_{2}\right), 1.27\left(\mathrm{~m}, 52 \mathrm{H}, \mathrm{CH}_{2}\right), 0.89\left(\mathrm{t}, J=5.41 \mathrm{~Hz}, 6 \mathrm{H}, \mathrm{CH}_{3}\right)$ ppm. ${ }^{13} \mathrm{C}$ NMR $\left(300 \mathrm{MHz}, \mathrm{CDCl}_{3}, \delta\right): 150.85,130.86$, 129.70, 127.62, 127.45, 126.60, 125.34, 119.97, 116.29, $68.66,31.86,30.25,29.62,29.50,29.30,29.05,25.36$, 22.63, 14.04 ppm. IR (oil): $v=1280$ (w, $\mathrm{P}=\mathrm{O}$ ), 1247 (s, $\mathrm{P}-\mathrm{O}-\mathrm{Ar}), 1016$ (s, P-O-CH$)_{2} \mathrm{~cm}^{-1}$. Anal. calcd. for $\mathrm{C}_{42} \mathrm{H}_{73} \mathrm{O}_{4} \mathrm{P}: \mathrm{C}, 74.96 ; \mathrm{H}, 10.93$; P, 4.60. Found: C, 74.99; $\mathrm{H}, 10.91 ; \mathrm{P}, 4.62$.

Compound 2a: red oil, yield $50 \% ;{ }^{1} \mathrm{H}$ NMR (300 $\mathrm{MHz}, \mathrm{CDCl}_{3}, \delta$ ): 7.80 (m, 8H, Ar H), 7.42 (m, 6H, Ar H), $4.32\left(\mathrm{~m}, 2 \mathrm{H}, \mathrm{O}-\mathrm{CH}_{2}\right), 1.72$ (quintet, $J=6.9 \mathrm{~Hz}, 2 \mathrm{H}, \mathrm{CH}_{2}$ ), $1.29\left(\mathrm{~m}, 10 \mathrm{H}, \mathrm{CH}_{2}\right), 0.86\left(\mathrm{t}, J=7.2 \mathrm{~Hz}, 3 \mathrm{H}, \mathrm{CH}_{3}\right) \mathrm{ppm}$. ${ }^{13} \mathrm{C}$ NMR $\left(300 \mathrm{MHz}, \mathrm{CDCl}_{3}, \delta\right): 148.25,133.82,131.02$, 129.91, 127.68, 127.54, 126.75, 125.59, 119.97, 116.68, 69.72, 31.64, 30.23, 29.05, 25.32, 22.55, 14.14 ppm. IR (oil): $v=1293$ (s, $\mathrm{P}=\mathrm{O}), 1241$ (s, P-O-Ar), 1039 (s, P-O- $\left.\mathrm{CH}_{2}\right) \mathrm{cm}^{-1}$. Anal. calcd. for $\mathrm{C}_{28} \mathrm{H}_{31} \mathrm{O}_{4} \mathrm{P}: \mathrm{C}, 72.71 ; \mathrm{H}$, 6.76; P, 6.70. Found: C, 72.68; H, 6.78; P, 6.72.

Compound 2b: red oil, yield $73 \%$; ${ }^{1} \mathrm{H}$ NMR $(300$ $\left.\mathrm{MHz}, \mathrm{CDCl}_{3}, \delta\right): 7.82(\mathrm{~m}, 8 \mathrm{H}, \mathrm{Ar} \mathrm{H}), 7.46(\mathrm{~m}, 6 \mathrm{H}, \mathrm{Ar} \mathrm{H})$, $4.35\left(\mathrm{~m}, 2 \mathrm{H}, \mathrm{O}-\mathrm{CH}_{2}\right), 1.74$ (quintet, $J=6.9 \mathrm{~Hz}, 2 \mathrm{H}, \mathrm{CH}_{2}$ ), $1.25\left(\mathrm{~m}, 14 \mathrm{H}, \mathrm{CH}_{2}\right), 0.90\left(\mathrm{t}, J=6.4 \mathrm{~Hz}, 3 \mathrm{H}, \mathrm{CH}_{3}\right) ;{ }^{13} \mathrm{C}$ NMR $\left(300 \mathrm{MHz}, \mathrm{CDCl}_{3}, \delta\right): 148.23,133.79,130.99$, $129.87,127.64,126.71,125.54,119.95,116.64,69.67$, 31.78, 30.20, 29.37, 29.19, 28.96, 25.97, 22.60, 14.03; IR (oil): $v=1293$ (s, $\mathrm{P}=\mathrm{O}$ ), 1241 (s, P-O-Ar), 1020 (s, $\left.\mathrm{P}-\mathrm{O}-\mathrm{CH}_{2}\right) \mathrm{cm}^{-1}$. Anal. calcd. for $\mathrm{C}_{30} \mathrm{H}_{35} \mathrm{O}_{4} \mathrm{P}$. C, $73.45 ; \mathrm{H}$, 7.19; P, 6.31. Found: C, 73.42; H, 7.22; P, 6.33 .

Compound 2c: red oil, yield $43 \%$; ${ }^{1} \mathrm{H}$ NMR $(300$ $\left.\mathrm{MHz}, \mathrm{CDCl}_{3}, \delta\right): 7.80(\mathrm{~m}, 8 \mathrm{H}, \mathrm{Ar} \mathrm{H}), 7.46(\mathrm{~m}, 6 \mathrm{H}, \mathrm{Ar} \mathrm{H})$, $4.34\left(\mathrm{~m}, 2 \mathrm{H}, \mathrm{O}-\mathrm{CH}_{2}\right), 1.73$ (quintet, $J=6.9 \mathrm{~Hz}, 2 \mathrm{H}, \mathrm{CH}_{2}$ ), $1.26\left(\mathrm{~m}, 18 \mathrm{H}, \mathrm{CH}_{2}\right), 0.90\left(\mathrm{t}, J=5.3 \mathrm{~Hz}, 3 \mathrm{H}, \mathrm{CH}_{3}\right) \mathrm{ppm}$. ${ }^{13} \mathrm{C}$ NMR (300 MHz, $\mathrm{CDCl}_{3}, \delta$ ): 148.21, 133.78, 130.98, 129.87, 127.64, 126.70, 126.20, 125.55, 119.93, 116.64, $69.68,31.83,30.19,29.53,29.42,29.36,29.26,28.96$, 25.29, 22.60, 14.03 ppm. IR (oil): $v=1293$ (s, $\mathrm{P}=\mathrm{O}$ ), 1241(s, P-O-Ar), 1020 (s, P-O- $\mathrm{CH}_{2}$ ) cm ${ }^{-1}$. Anal. calcd. for $\mathrm{C}_{32} \mathrm{H}_{39} \mathrm{O}_{4} \mathrm{P}: \mathrm{C}, 74.11 ; \mathrm{H}, 7.58 ; \mathrm{P}, 5.97$. Found: C, 74.14; H, 7.62; P, 5.95 .

Compound 2d: red oil, yield 55\%; ${ }^{1} \mathrm{H}$ NMR (300 $\left.\mathrm{MHz}, \mathrm{CDCl}_{3}, \delta\right): 7.80(\mathrm{~m}, 8 \mathrm{H}, \mathrm{Ar} \mathrm{H}), 7.45(\mathrm{~m}, 6 \mathrm{H}, \mathrm{Ar} \mathrm{H})$, $4.33\left(\mathrm{~m}, 2 \mathrm{H}, \mathrm{O}-\mathrm{CH}_{2}\right), 1.73$ (quintet, $J=6.8 \mathrm{~Hz}, 2 \mathrm{H}, \mathrm{CH}_{2}$ ), $1.26\left(\mathrm{~m}, 22 \mathrm{H}, \mathrm{CH}_{2}\right), 0.89\left(\mathrm{t}, J=5.9 \mathrm{~Hz}, 3 \mathrm{H}, \mathrm{CH}_{3}\right) \mathrm{ppm}$. ${ }^{13} \mathrm{C}$ NMR (300 MHz, $\mathrm{CDCl}_{3}, \delta$ ): 148.20, 133.77, 130.98, 129.87, 129.36, 127.64, 126.70, 125.55, 119.92, 116.64, $69.69,31.84,30.19,29.57,29.42,29.28,28.96,25.28$, 22.61, 14.10 ppm. IR (oil): $v=1280$ (s, $\mathrm{P}=\mathrm{O}$ ), 1243 (s, $\mathrm{P}-\mathrm{O}-\mathrm{Ar}$ ), 1036 (s, P-O-CH$)_{2} \mathrm{~cm}^{-1}$. Anal. calcd. for $\mathrm{C}_{34} \mathrm{H}_{43} \mathrm{O}_{4} \mathrm{P}: \mathrm{C}, 74.70 ; \mathrm{H}, 7.93$; P, 5.67. Found: C, 74.73; $\mathrm{H}, 7.91 ; \mathrm{P}, 5.68$.

Compound 2e: red oil, yield $48 \% ;{ }^{1} \mathrm{H}$ NMR (300 $\left.\mathrm{MHz}, \mathrm{CDCl}_{3}\right), \delta$ ): $7.42(\mathrm{~m}, 8 \mathrm{H}, \mathrm{Ar} \mathrm{H}), 7.30(\mathrm{~m}, 6 \mathrm{H}, \mathrm{Ar}$ $\mathrm{H}), 4.32\left(\mathrm{~m}, 2 \mathrm{H}, \mathrm{O}-\mathrm{CH}_{2}\right), 1.71$ (quintet, $J=7.2 \mathrm{~Hz}, 2 \mathrm{H}$, $\left.\mathrm{CH}_{2}\right), 1.25\left(\mathrm{~m}, 26 \mathrm{H}, \mathrm{CH}_{2}\right), 0.87\left(\mathrm{t}, J=6.6 \mathrm{~Hz}, 3 \mathrm{H}, \mathrm{CH}_{3}\right)$ ppm. ${ }^{13} \mathrm{C}$ NMR $\left(300 \mathrm{MHz}, \mathrm{CDCl}_{3}, \delta\right): 145.73,131.31$, 128.52, 127.42, 125.19, 124.26, 123.11, 117.48, 114.18, 67.24, 29.39, 28.39, 27.73, 27.16, 26.98, 26.83, 26.51, 22.83, 20.16, 11.59 ppm. IR (oil): $v=1299$ (w, $\mathrm{P}=\mathrm{O}$ ), 1243 (w, P-O-Ar), 1020 (s, P-O-CH cm $^{-1}$. Anal. calcd. for $\mathrm{C}_{36} \mathrm{H}_{47} \mathrm{O}_{4} \mathrm{P}: \mathrm{C}, 75.23 ; \mathrm{H}, 8.24 ; \mathrm{P}, 5.39$. Found: $\mathrm{C}$, 75.20; H, 8.27; P, 5.41.

\subsection{Formation of the Hybrids}

Varying weighted amounts of MWCNT (between $1 \times$ $10^{-4}$ and $8 \times 10^{-4} \mathrm{~g}$ ) were dispersed, for 30 minutes, by sonication in ca. $20 \mathrm{~mL}$ of $\mathrm{CHCl}_{3}$ at an ultrasound power of $200 \mathrm{~W}$ and a temperature of $25^{\circ} \mathrm{C}$. $\mathrm{A} \mathrm{CHCl}_{3}$ solution $(100 \mu \mathrm{L})$ of phosphate ester additive $(0.1 \mathrm{M})$ was added 
to the MWCNT dispersions and the resulting systems were again sonicated for further 30 minutes under the same condition previously reported. The final volume of the obtained dispersions was $100 \mathrm{~mL}$ and the concentration of additive was $1 \times 10^{-4} \mathrm{M}$.

\section{Results and Discussion}

\subsection{Formation and Stability of the Hybrids}

The synthesis of phosphate esters, involved in the formation of hybrids was carried out in the first by reaction between the alcohols, with chain length variable, and a suitable amount of $\mathrm{POCl}_{3}$ and then crude compounds were reacted with the aromatic $\beta$-naphthol to obtained the compounds 1,2 a-e (Figure 2). Phosphate esters obtained were used in the formation of hybrids in a concentration range lower than that of micellization [21]. The formation of hybrids was carried out by adding $1 \times 10^{-4}$ $\mathrm{M}$ of phosphate ester to a "dispersion", at increasing amount, of pristine MWCNTs in $\mathrm{CHCl}_{3}$. Successful functionalization was immediately visible, resulting in the formation of dark dispersions, where the change of color intensity provides a qualitative indication of the amount of nanotube present (Figure 3(a)). By contrast, MWCNTs precipitated out almost completely, after the same sonication protocol, when the phosphate ester was not added (Figure 3(b)). Considering that the stability of a dispersion is the result of a delicate balance of attractive and repulsive forces, it seemed that the improved MWCNT dispersibility is due to the interaction between aryl groups and the CNT surface, [12] because chain phosphate esters, which do not include any conjugated

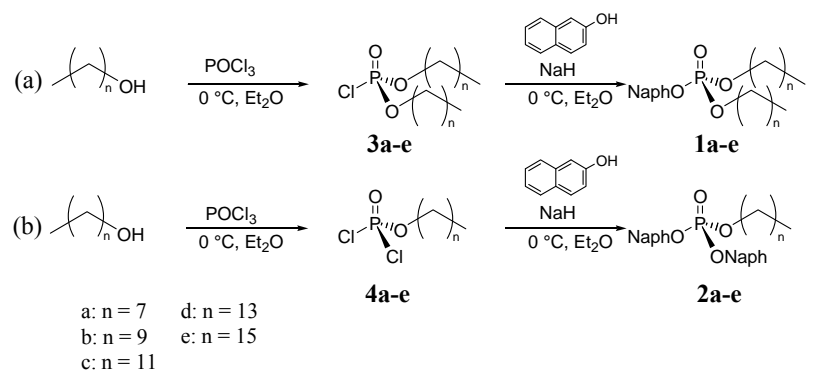

Figure 2. Scheme of synthesis of phosphate ester derivatives 1,2 a-e.

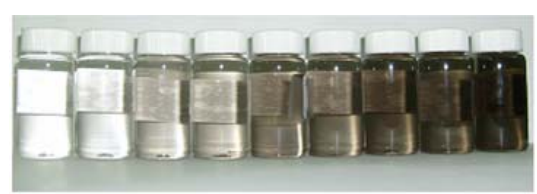

(a)

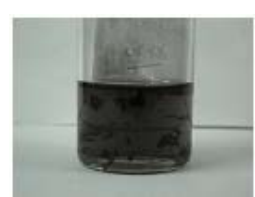

(b)
Figure 3. (a) Dispersions of MWCNT (from 0 to $8 \times 10^{-6}$ $\mathrm{g} / \mathrm{mL}$ ) obtained after sonication protocol with of phosphate ester $1 \mathrm{c}\left(1 \times 10^{-4} \mathrm{M}\right)$ in $\mathrm{CHCl}_{3}$; (b) Dispersion of pristine MWCNT in $\mathrm{CHCl}_{3}$. structure, were weakly adsorbed on the CNT surfaces and gave rise to a slight increase in the CNT dispersibility in chloroform. The dispersions were stable from one (2a-e) to at least three (1a-e) weeks. Dispersion stability was assessed by UV-vis analysis. Different dispersions, at varying amounts of MWCNTs $\left(3 \times 10^{-6}, 5 \times 10^{-6}\right.$ and $8 \times 10^{-6} \mathrm{~g} / \mathrm{mL}$ respectively) and fixed concentration of 1 $\left(1 \times 10^{-4} \mathrm{M}\right)$ were monitored for three weeks. The change in absorbance, at $272 \mathrm{~nm}$ (see below) as a function of time was observed. Indeed, the values of absorbance of MWCNTs pristine and phosphate esters 1a-e were 0.12 and ca. 0.5 , respectively, in contrast all hybrids showed absorbance values higher than 1.1 at time 0 ; this denotes that there was an interaction between phosphate esters and MWCNTs and so the hybrids formation. In Figure 4(a) is shown the plot of the absorbance as a function of time for dispersion with a MWCNT concentration of $5 \times 10^{-6} \mathrm{~g} / \mathrm{mL}$. In this case we observed a curve that reach a plateau after ca. three weeks and the absorbance values recorded were ca. 1.3. After three weeks, a slight precipitation of MWCNTs was, also, observed. The same considerations can be made for the dispersion with a MWCNT concentration of $3 \times 10^{-6} \mathrm{~g} / \mathrm{mL}$. In

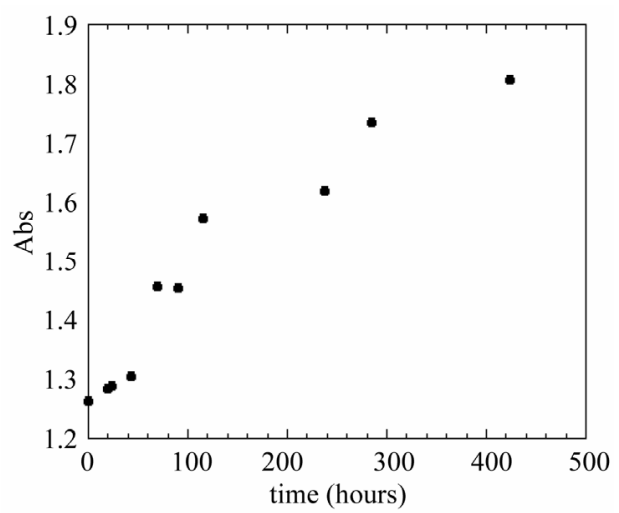

(a)

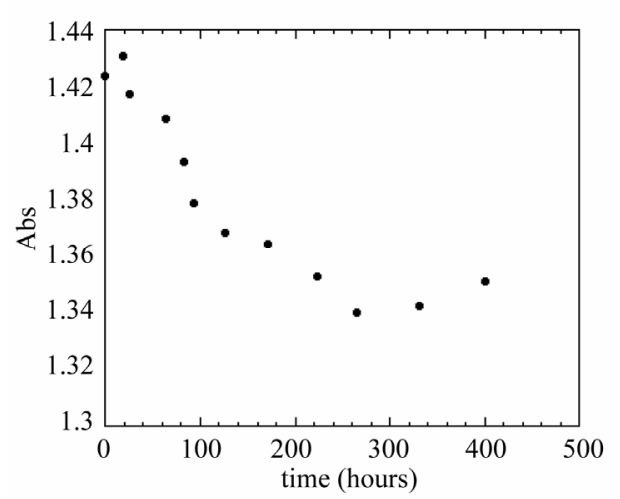

(b)

Figure 4. Plot of the absorbance as a function of time for dispersion with a MWCNT concentration of (a) $5 \times 10^{-6}$ $\mathrm{g} / \mathrm{mL}$, (b) $8 \times 10^{-6} \mathrm{~g} / \mathrm{mL}$ in the presence of phosphate ester 1c. 
Figure 4(b) is shown the plot of the absorbance as a function of time for the dispersion with MWCNT concentration of $8 \times 10^{-6} \mathrm{~g} / \mathrm{mL}$. In this case we observed a different behavior; in fact, the absorbance value (1.42) initially decreases in a linear manner until at a value of ca. 1.3 after 300 hours, successively, a slight precipitation was observed too. Experimental data collected, showed that dispersions of hybrids with phosphate esters 2a-e were less stable. The greater stability of the hybrids dispersions with phosphate esters 1a-e than with phosphate esters 2a-e can be explained admitting that compounds 1a-e, with two alkyl chains, wrap the MWCNT surface more efficiently than the stiff compounds $\mathbf{2 a - e}$, in spit of their higher $\pi$ surface. Probably, because the absorbance variations are similar for the two ester classes it is possible to deduce that only one aromatic ring interacts with MWCNT surface, so the different stability is determined by alkyl chains length.

\subsection{Studies of Interaction between MWCNTs and Phosphate Ester}

\subsubsection{Uv-vis Spectroscopy}

Uv-vis spectroscopy was, also, employed to confirm the good dispersing ability of the phosphate ester derivatives towards MWCNTs. In particular we recorded the UV-vis spectra in chloroform at $25^{\circ} \mathrm{C}$ and a fixed concentration of the additive $\left(1 \times 10^{-4} \mathrm{M}\right)$ in the presence of varying amounts of MWCNTs $\left(0-8 \times 10^{-6} \mathrm{~g} / \mathrm{mL}\right)$. The occurrence of the binding was evaluated by measuring the absorbance at $272 \mathrm{~nm}$ (corrected for the contribution due to the MWCNTs), which corresponds to the maximum absorption band of the phosphate ester. Typical trends are illustrated in Figure 5.

Two different behaviors were observed depending on the phosphate ester structure. In some cases (1a-c, 2a-c), i.e. for additives having a chain length not exceeding 12 carbon atoms, absorbance increases up to a MWCNT concentration of ca. $6 \times 10^{-6} \mathrm{~g} / \mathrm{mL}$, and then shows a plateau at higher concentrations. This could indicate that progressive formation of hybrids occurs until a saturation level is reached. On the other hand, for additives having longer carbon chains (1d-e, 2d-e), no saturation trend is observed.

Similar trends were observed by Morishita et al. that prepared macromer-grafted polymers containing suitable side chains and pyrene units for improving absorption on MWCNT surface. They observed, by UV-vis spectroscopy, that absorbance of hybrids was saturated as a function of the specific surface area of the MWCNTs used [15].

Furthermore, in the case of compound $\mathbf{1 c}$, we recorded the UV-vis spectra in chloroform at $25^{\circ} \mathrm{C}$ and a fixed concentration of MWCNT $\left(2 \times 10^{-6} \mathrm{~g} / \mathrm{mL}\right)$ in the presence of varying amounts of phosphate ester $\left(0-3 \times 10^{-4}\right.$

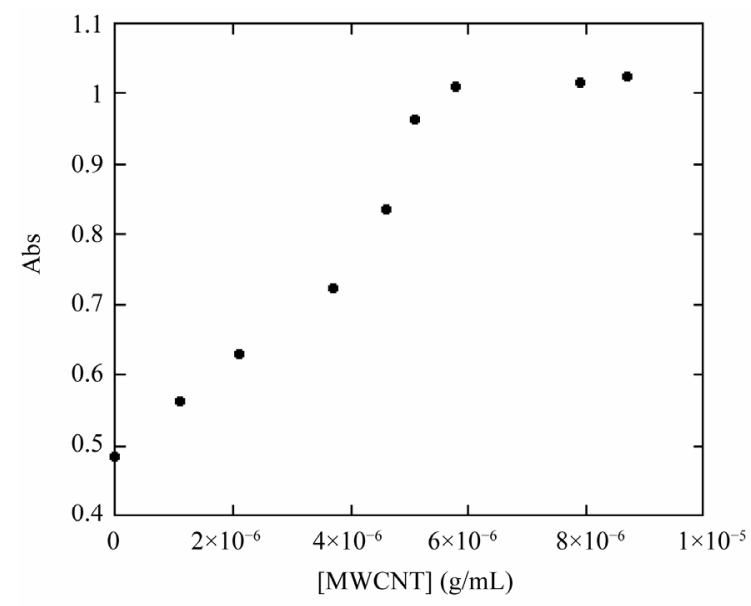

(a)

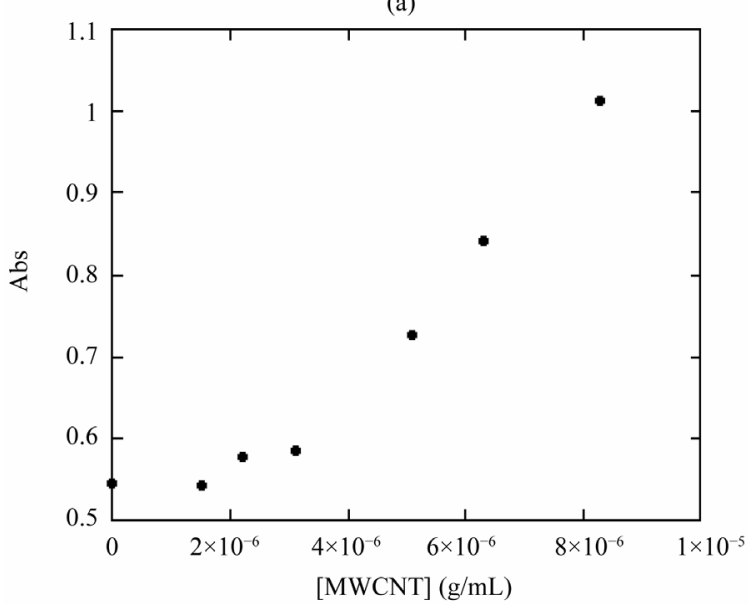

(b)

Figure 5. Trend of the absorbance of the hybrid with the phosphate ester (a) 1c, (b) 1e as function of MWCNT concentration (from 0 to $8 \times 10^{-6} \mathrm{~g} / \mathrm{mL}$ ).

M). In Figure 6 is shown the plot of the absorbance (corrected for the contribution due to the ester) as a function of 1c concentration that confirms the formation of hybrids. At ester concentration higher than $3 \times 10^{-4} \mathrm{M}$ absorbance values are affected by formation of micelles.

\subsection{2. ${ }^{31}$ P-NMR Spectroscopy}

The interaction between phosphate esters and MWCNTs was, also, studied by means of ${ }^{31} \mathrm{P}-\mathrm{NMR}$ spectroscopy. Spectra were recorded in $\mathrm{CHCl}_{3}$ using $\mathrm{D}_{3} \mathrm{PO}_{4}$ as an internal reference standard. Small but significant downfield shift of the ${ }^{31} \mathrm{P}$ signal was observed for the peak relevant to the phosphate group of all compounds on increasing the amount of MWCNTs. This variation accounts for a change of the chemical environment for the phosphorus atom, consequent to the binding onto the MWCNT surface. The change in chemical shift of the phosphorus atom, though small, has been indeed considered significant in previous studies [22].

The ${ }^{31} \mathrm{P}$ shift vs. MWCNT concentration gives a bell- 


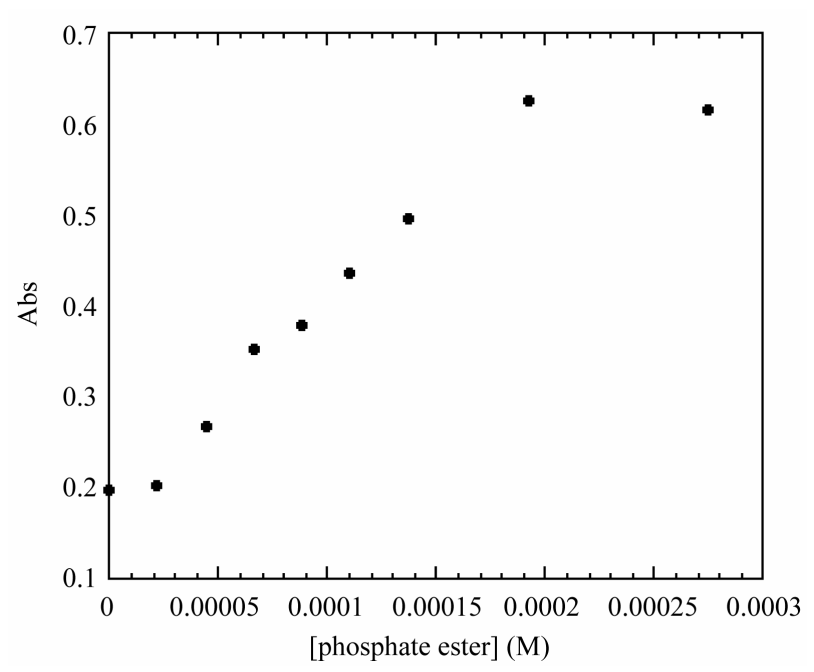

Figure 6. Trend of the absorbance of the MWCNT hybrid as function of $1 \mathrm{c}$ concentration (from 0 to $3 \times 10^{-4} \mathrm{M}$ ).

shaped curve, with a maximum at around ca. $4 \times 10^{-6}$ $\mathrm{g} / \mathrm{mL}$ (Figure 7). This behavior is probably due to the release of the phosphate ester when the MWCNT concentration is higher, because nanotubes prefer to aggregate each other again.

Therefore, data indicate that the adsorption of the organic molecules onto MWCNT surface is dependent, not only by the length of the side chain, but also by the concentration of MWCNTs. It is also interesting to notice that the downfield shift suggests a weakening of the P-O interaction in the molecule consequent to binding. The same observations can be made for compound 2 a-e.

We have, also, recorded ${ }^{31} \mathrm{P}$ spectra as a function of the side chain length for compounds 2a-e and 1a-e at the same concentration of MWCNTs $\left(4 \times 10^{-6} \mathrm{~g} / \mathrm{mL}\right)$. In this case weren't great differences in chemical shift and the results were similar to those obtained by UV-vis spectroscopy.

\subsubsection{Raman Spectroscopy}

Raman spectroscopy was used to investigate the structural modification of MWCNTs as a consequence of the interaction with the phosphate esters. As an example, the Raman spectra of pristine MWCNTs and of the hybrids with phosphate esters $\mathbf{1 b}$ and $\mathbf{1 d}$ are reported in Figure $\mathbf{8}$.

The Raman spectrum of pristine MWCNTs exhibits D-band and G-band centred at around 1339 and $1572 \mathrm{~cm}^{-1}$, respectively. The D-band is attributed to the presence of disordered structures, such as defective CNTs and deformation vibrations of a hexagonal ring and amorphous carbon, while the G-band is related to the vibration of $\mathrm{sp}^{2}$-bonded carbon atoms in a two-dimensional hexagonal lattice, such as in a graphitic layer. The Raman spectra of most of the samples show the same bands of the pristine MWCNTs. Only in the Raman spectra of the

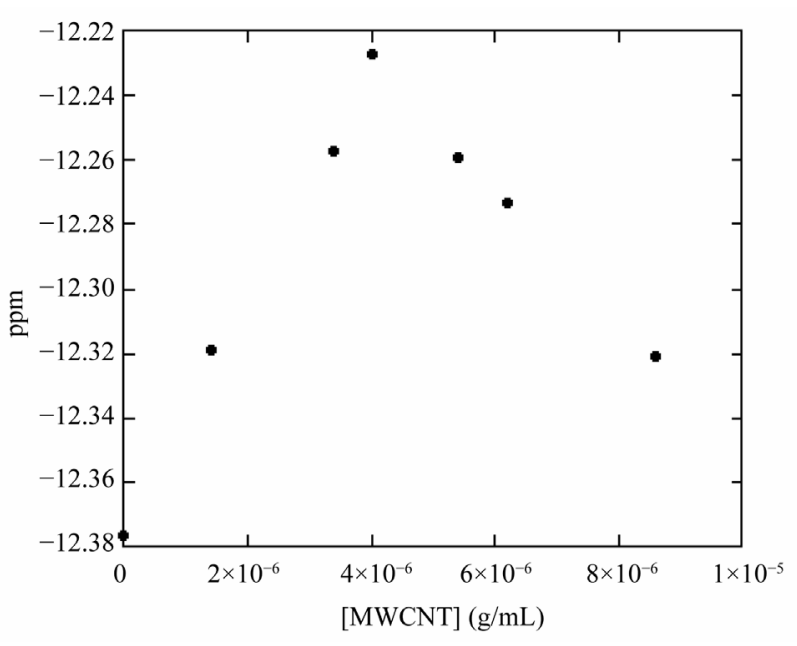

Figure 7. ${ }^{31} \mathrm{P}$ chemical shift of the hybrid with the phosphate ester $1 \mathrm{a}\left(1 \times 10^{-4} \mathrm{M}\right)$ vs. MWCNT concentration (from 0 to $8 \times 10^{-6} \mathrm{~g} / \mathrm{mL}$ ).

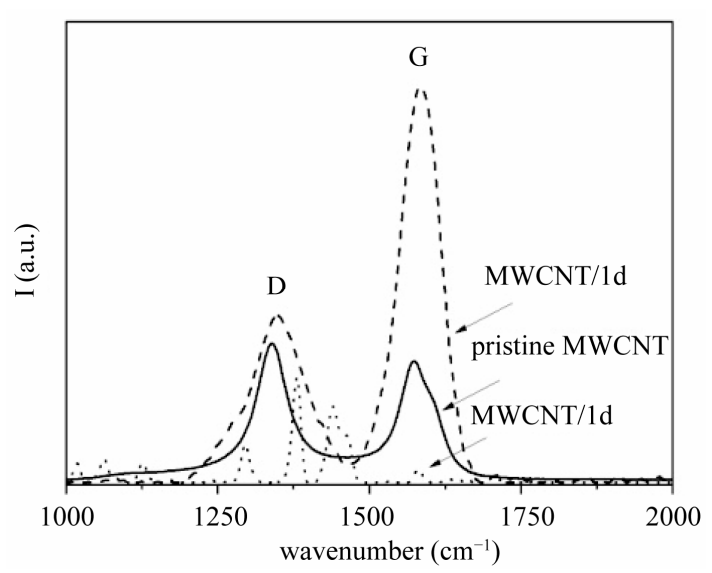

Figure 8. Raman spectra of pristine MWCNTs and hybrids with phosphate esters $1 \mathrm{~b}$ and $1 \mathrm{~d}$.

hybrids with phosphate esters $\mathbf{1 b}, \mathbf{1 e}$ and $\mathbf{2 b}$, the characteristic bands of MWCNTs are covered by the organic molecules signals. In particular, the observed bands at 1581 and $1441 \mathrm{~cm}^{-1}$ are due to the $\mathrm{C}=\mathrm{C}$ stretching bands of the aromatic ring of naphthalene, while the ones observed at 1380, 1018 and $1063 \mathrm{~cm}^{-1}$ are assigned to the $\mathrm{C}-\mathrm{H}$ in-plane deformation vibrations. The observed bands at 1294,1125 and $767 \mathrm{~cm}^{-1}$ can be ascribed to the $\mathrm{C}-\mathrm{O}$ stretching vibrations, to the $\mathrm{P}-\mathrm{O}-\mathrm{C}$ stretching vibrations and to the $\mathrm{P}=\mathrm{O}$ vibration of the phosphate group, respectively. In addition, the symmetric and asymmetric stretching vibration of $-\mathrm{CH}_{3}$ and $-\mathrm{CH}_{2}$ are observed in the range $2700-3000 \mathrm{~cm}^{-1}$.

A G-band shifts and a variation of the intensity of D and $\mathrm{G}$ bands is noticeable in the hybrids when compared to the MWCNTs pristine, thus suggesting changes in the structure of MWCNTs. The G-band position and the $\mathrm{I}_{\mathrm{G}} / \mathrm{I}_{\mathrm{D}}$ ratio for each hybrid were reported in Table 1. 
Table 1. Wavenumber of the Raman bands and scattering intensities ratio $\left(I_{G} / I_{D}\right)$ of pristine and functionalized MWCNTs.

\begin{tabular}{lccc}
\hline Sample & G-band $\left(\mathrm{cm}^{-1}\right)$ & D-band $\left(\mathrm{cm}^{-1}\right)$ & $\mathrm{I}_{\mathrm{G}} / \mathrm{I}_{\mathrm{D}}$ \\
\hline MWCNTs & $1572(1)$ & $1339(1)$ & 0.94 \\
MWCNTs/1a & $1586(1)$ & $1349(1)$ & 1.09 \\
MWCNTs/1b & $/$ & $/$ & $/$ \\
MWCNTs/1c & $1582(1)$ & $1347(1)$ & 2.89 \\
MWCNTs/1d & $1584(1)$ & $1347(1)$ & 2.28 \\
MWCNTs/1e & $/$ & $/$ & $/$ \\
MWCNTs/2a & $1581(1)$ & $1378(1)$ & 1.10 \\
MWCNTs/2b & $/$ & $/$ & $/$ \\
MWCNTs/2c & $1585(1)$ & $1346(1)$ & 2.38 \\
MWCNTs/2d & $1582(1)$ & $1352(1)$ & 1.68 \\
MWCNTs/2e & $1587(1)$ & $1344(1)$ & 2.19 \\
\hline
\end{tabular}

The changes on G-band can be explained by the strong attachment of phosphate esters with MWCNT surface and the shift could be another indication of interaction between phosphate esters and MWCNTs; indeed, van der Waals forces between alkyl chain and MWCNTs surface affect the vibration of the graphene sheet, which generates the peaks of G-band, resulting into the change in the frequency [23].

Since the $\mathrm{I}_{\mathrm{G}} / \mathrm{I}_{\mathrm{D}}$ ratio indicates the MWCNTs purity, the observed increase of the $\mathrm{I}_{\mathrm{G}} / \mathrm{I}_{\mathrm{D}}$ ratio values for hybrids could be due "to the passivation of dangling bonds" in the curved graphene sheets in MWCNTs [24]; so it's possible that, during the functionalization, amorphous carbon is removed from the surface. As it can be noted, the values of the $I_{G} / I_{D}$ ratio increase with increasing of the alkyl chain length. In particular, these values are highest for phosphate esters with at least 12 carbon atoms.

\subsection{Hybrids Morphology: SEM Investigations}

In order to evaluate possible modifications on the MWCNTs morphology due to the functionalization, a SEM investigation was performed. Pristine MWCNTs was also observed to perform the comparison. Figure 9 shows the SEM micrographs of the a) pristine MWCNTs and b) hybrid with the phosphate ester 1c. It is seen in Figure 9(a) that MWCNTs are entangled to each other, however individual MWCNTs can be easily distinguished. When the functionalization occurred, MWCNTs bundles appear exfoliated, this phenomenon could be due to $\pi-\pi$ and van der Waals interactions with the phosphate ester 1c (Figure 9(b)) [25].

\subsection{Thermal Stability of Hybrids: Thermogravimetric Analysis}

Thermogravimetric measurements were performed to
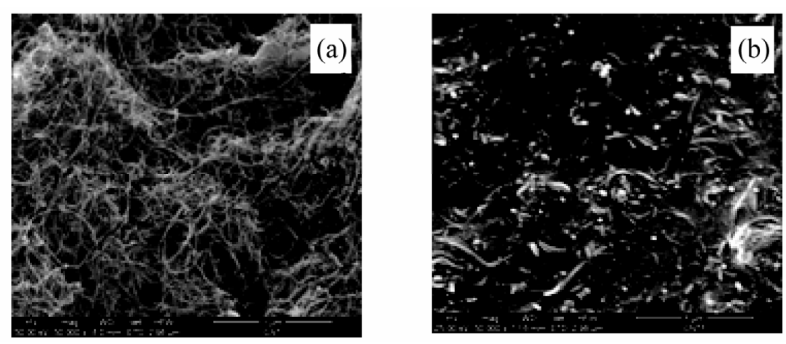

Figure 9. SEM micrographs of (a) pristine MWCNTs, (b) hybrid with the phosphate ester $1 \mathrm{c}$.

determine the thermal stability of MWCNT hybrids; for a proper discussion of them, TG experiments were carried out also on the pristine components. The TG curves under nitrogen atmosphere are shown in Figure 10. For pristine nanotubes, the onset of significant weight loss occurs around $570^{\circ} \mathrm{C}$, and a sharp weight loss, $25.8 \%$, happens thereafter. This relevant weight loss occurring above $570^{\circ} \mathrm{C}$ is related to degradation of disordered amorphous carbon as reported in literature [26,27]. For the functionalized MWCNTs it is observed a weight loss starting at ca. $285^{\circ} \mathrm{C}$, which is related to the decomposition of the phosphate esters, while the nanotubes do not exhibit weight loss until $900^{\circ} \mathrm{C}$ under nitrogen atmosphere, indicating a high purity [28]. This last result is due to the removal of amorphous carbon from the nanotube surface confirming the Raman spectroscopy analysis. Moreover, TGA allowed us to estimate the degree of functionalization of hybrids by determining the percentage weight fraction of each single component in the hybrid by using an approach reported in literature $[29,30]$. Briefly, we focused attention on the residual matter at $500^{\circ} \mathrm{C}$; assuming that the interactions between phosphate esters and MWCNTs in the hybrid do not alter the residual matter of pristine components, the percentage weight fraction of phosphate esters $\left(C_{P E}\right)$ is calculated as

$$
C_{P E}=100 \cdot\left(\frac{M R 500_{N}-M R 500_{N-P E}}{M R 500_{N}-M R 500_{P E}}\right)
$$

where $M R 500_{N}, M R 500_{P E}$ and $M R 500_{N-P E}$ are the residual matter at $500^{\circ} \mathrm{C}$ for MWCNT, phosphate esters and MWCNTs/phosphate esters, respectively. We determined that $C_{P E}$ is equal to $75 \%$ indicating a relevant degree of functionalization.

\section{Conclusion}

The MWCNTs/phosphate ester hybrids were prepared. Dispersions in $\mathrm{CHCl}_{3}$ obtained after a sonication were stable one week for compounds with two naphtalenic rings (2a-e) whilst a rise in time was observed for phosphate esters with one naphtalenic ring (1a-e). This unexpected behavior could imply that the van der Waals interactions between the long side chains of phosphate 


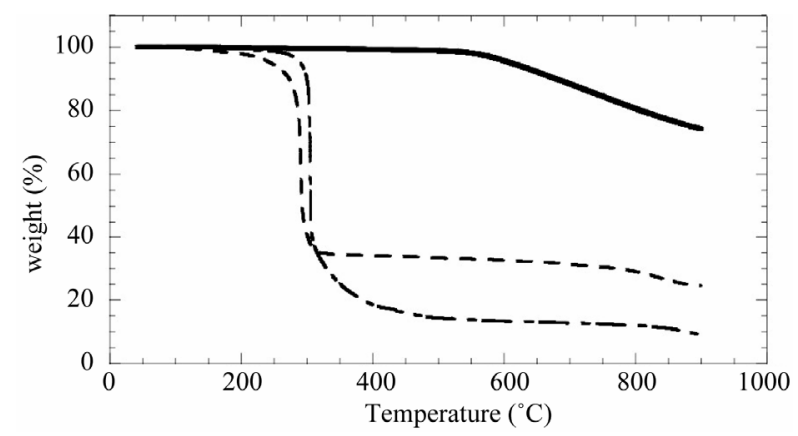

Figure 10. Curves of mass loss to temperature (TG) for MWCNTs (-), phosphate ester 1c (- - -) and hybrid with phosphate ester $1 \mathrm{c}(---)$.

esters and MWCNT surfaces could be more influent, in this case, than a second $\pi-\pi$ interaction between the naphtalenic rings and MWCNT surface. The change in morphology of the MWCNTs after functionalization was analysed by SEM micrograph in comparison with pristine MWCNTs. The UV-vis and ${ }^{31} \mathrm{P}-\mathrm{NMR}$ experiments showed a variation in the spectra recorded at varying concentrations of MWCNTs. In particular, the trend of absorbance as function of MWCNT concentration showed two different behaviors depending on the phosphate ester structure. In our opinion when more of 12 carbon atoms are present in the side chain of phosphate ester, no saturation trend occurred because the free MWCNT surface is not enough for all of phosphate derivatives. In contrast, no significative variations were observed when the spectra were recorded as a function of the side chain length of the phosphate esters. The Raman spectrum of hybrids showed a change on the G-bands shift and on the value of $\mathrm{I}_{\mathrm{G}} / \mathrm{I}_{\mathrm{D}}$ ratio, that confirms the interaction between phosphate ester and MWCNT surface. From the TGA results it could be concluded that the non covalent functionalization of MWCNT surface with phosphate ester could enhance the thermal stability of the nanotube. The observed good stability of the hybrids dispersions is a preliminary study of a future purpose to their incorporation in a polymeric matrix to produce phosphorilated MWCNTs/polymer composites, that should have enhanced properties of the pristine polymer.

\section{Acknowledgements}

Financial support from the University of Palermo is gratefully acknowledged. The authors would like to thank Mr. M. Cascino (Università degli Studi di Palermo) for precious contribution for collection of ${ }^{31} \mathrm{P}$ NMR spectra; Prof. C. Mazzocchia (Politecnico di Milano, Italy) for providing the MWCNTs.

\section{REFERENCES}

[1] S. Iijima, "Helical Microtubules of Graphitic Carbon,"
Nature, Vol. 354, No. 6348, 1991, pp. 56-58. doi: $10.1038 / 354056 \mathrm{a} 0$

[2] P. M. Ajayan, "Nanotubes from Carbon," Chemical Reviews, Vol. 99, No. 7, 1999, pp. 1787-1799. doi: $10.1021 / \mathrm{cr} 970102 \mathrm{~g}$

[3] B. S. Shim, J. Zhu, E. Jan, K. Critchley, S. Ho, P. Podsiadlo, K. Sun and N. A. Kotov, "Multiparameter Structural Optimization of Single-Walled Carbon Nanotube Composites: Toward Record Strength, Stiffness, and Toughness," ACS Nano, Vol. 3, No. 7, 2009, pp. 1711-1722. doi:10.1021/nn9002743

[4] T. Wu, Y. Pan, H. Bao and L. Li, "Preparation and Properties of Chitosan Nanocomposite Films Reinforced by Poly(3,4-Ethylenedioxythiophene)-Poly-(Styrenesulfonat e) Treated Carbon Nanotubes," Materials Chemistry and Physics, Vol. 129, No. 3, 2011, pp. 932-938. doi:10.1016/j.matchemphys.2011.05.030

[5] R. Jung, S. H. Yoon, M. Kang, H.-S. Kim and H.-J. Jin, "Preparation of Carbon Nanotubes-Incorporated Polymeric Microspheres for Electrorheological Fluids," Current Applied Physics, Vol. 8, No. 6, 2008, pp. 807-809. doi:10.1016/j.cap.2007.04.033

[6] M. Ouyang, J. L. Huang and C. M. Lieber, "Fundamental Electronic Properties and Applications of Single-Walled Carbon Nanotubes," Accounts of Chemical Research, Vol. 35, No. 12, 2002, pp. 1018-1025. doi:10.1021/ar0101685

[7] A. Hirsch, "Functionalization of Single-Walled Carbon Nanotubes," Angewandte Chemie International Edition, Vol. 41, No. 11, 2002, pp. 1853-1859.

doi:10.1002/1521-3773(20020603)41:11<1853::AID-AN IE1853>3.0.CO;2-N

[8] T. Tang, Z. Shi and J. Yin, "Poly(Benzimidazole) Functionalized Multi-Walled Carbon Nanotubes $/ 100 \%$ Acidified Poly(Hydroxyaminoether) Composites: Synthesis, Characterization and Properties," Materials Chemistry and Physics, Vol. 129, No. 1-2, 2011, pp. 356-364.

[9] M. Prato, K. Kostarelos and A. Bianco, "Functionalized Carbon Nanotubes in Drug Design and Discovery," Accounts of Chemical Research, Vol. 41, No. 1, 2008, pp. 60-68. doi:10.1021/ar700089b

[10] R. J. Chen, Y. Zhang, D. Wang and H. Dai, "Noncovalent Sidewall Functionalization of Single-Walled Carbon Nanotubes for Protein Immobilization," Journal of the American Chemical Society, Vol. 123, No. 16, 2001, pp. 38383839. doi: $10.1021 / \mathrm{ja} 010172 \mathrm{~b}$

[11] O.-K. Kim, J. Je, J. W. Baldwin, S. Kooi, P. E. Pehrsson and L. J. Buckley, "Solubilization of Single-Wall Carbon Nanotubes by Supramolecular Encapsulation of Helical Amylose," Journal of the American Chemical Society, Vol. 125, No. 15, 2003, pp. 4426-4427. doi:10.1021/ja029233b

[12] A. Star, Y. Liu, K. Grant, L. Ridvan, J. F. Stoddart, D. W. Steuerman, M. R. Diehl, A. Boukai and J. R. Heath, "Noncovalent Side-Wall Functionalization of Single-Walled Carbon Nanotubes," Macromolecules, Vol. 36, No. 3, 2003, pp. 553-560. doi:10.1021/ma021417n

[13] D. M. Guldi, G. M. A. Rahman, N. Jux, N. Tagmatarchis and M. Prato, "Integrating Single-Wall Carbon Nanotubes 
into Donor-Acceptor Nanohybrids," Angewandte Chemie International Edition, Vol. 43, No. 41, 2004, pp. 55265530. doi:10.1002/anie.200461217

[14] Y.-L. Zhao, L. Hu, J. F. Stoddart and G. Gruner, "Pyrenecyclodextrin-Decorated Single-Walled Carbon Nanotube Field-Effect Transistors as Chemical Sensors," $A d$ vanced Materials, Vol. 20, No. 10, 2008, pp. 1910-1915. doi:10.1002/adma.200702804

[15] T. Morishita, M. Matsushita, Y. Katagiri and K. Fukumori, "Synthesis and Properties of Macromer-Grafted Polymers for Noncovalent Functionalization of Multiwalled Carbon Nanotubes," Carbon, Vol. 47, No. 11, 2009, pp. 2716-2726. doi:10.1016/j.carbon.2009.05.032

[16] K. Petrie, A. Docoslis, S. Vasic, M. Kontopoulou, S. Morgan and Z. Ye, "Non-Covalent/Non-Specific Functionalization of Multi-Walled Carbon Nanotubes with a Hyperbranched Polyethylene and Characterization of Their Dispersion in a Polyolefin Matrix," Carbon, Vol. 49, No. 10, 2011, pp. 3378-3382. doi:10.1016/j.carbon.2011.04.001

[17] A. Di Crescenzo, R. Germani, E. Del Canto, S. Giordani, G. Savelli and A. Fontana, "Effect of Surfactant Structure on Carbon Nanotube Sidewall Adsorption," European Journal of Organic Chemistry, Vol. 28, 2011, pp. 56415648. doi:10.1002/ejoc. 201100720

[18] V. J. Mkhabela, A. K. Mishra and X. Y. Mbianda, "Thermal and Mechanical Properties of Phosphorylated Multiwalled Carbon Nanotube/Polyvinyl Chloride Composites," Carbon, Vol. 49, No. 2, 2011, pp. 610-617. doi:10.1016/i.carbon.2010.10.006

[19] J. Xu and L. Guan, "Diameter Selective Band Structure Modification of Single-Walled Carbon Nanotubes by Encapsulated Phosphorus Chains," The Journal of Physical Chemistry C, Vol. 113, No. 34, 2009, pp. 15099-15101. doi:10.1021/ip906056n

[20] J. Liu, H. Liu, H. Zhang, R. Li, G. Liang, M. Gauthier and X. Sun, "Synthesis and Characterization of Phosphorus-Nitrogen Doped Multi-Walled Carbon Nanotubes," Carbon, Vol. 49, No. 15, 2001, pp. 5014-5021. doi:10.1016/j.carbon.2011.07.018

[21] K. Kalyanasundaram and J. K. Thomas, "Environmental Effects on Vibronic Band Intensities in Pyrene Monomer Fluorescence and Their Application in Studies of Micellar Systems," Journal of the American Chemical Society, Vol. 99, No. 7, 1977, pp. 2039-2044. doi:10.1021/ja00449a004

[22] Y. Ding, L. Zhang, J. Xie and R. Guo, "Characteristics and Molecular Mechanism of Interaction between Ionic
Liquid and DNA," The Journal of Physical Chemistry B, Vol. 114, No. 5, 2010, pp. 2033-2043.

doi:10.1021/jp9104757

[23] W. Zhou, S. Lv and W. Shi, "Preparation of MicelleEncapsulated Single-Wall and Multi-Wall Carbon Nanotubes with Amphiphilic Hyperbranched Polymers," European Polymer Journal, Vol. 44, No. 3, 2008, pp. 587-601. doi:10.1016/j.eurpolymj.2008.01.020

[24] A. S. Patole, S. P. Patole, J.-B. Yoo, J.-H. Ahn and T.-H. Kim, "Effective in Situ Synthesis and Characteristics of Polystyrene Nanoparticle-Covered Multiwall Carbon Nanotube Composite," Journal of Polymer Science Part B: Polymer Physics, Vol. 47, No. 15, 2009, pp. 1523-1529. doi:10.1002/polb.21754

[25] C. Tang, T. Zhou, J. Yang, Q. Zhang, F. Chen, Q. Fu and L. Yang, "Wet-Grinding Assisted Ultrasonic Dispersion of Pristine Multi-Walled Carbon Nanotubes (MWCNTs) in Chitosan Solution," Colloids and Surfaces B: Biointerfaces, Vol. 86, No. 1, 2011, pp. 189-197. doi:10.1016/j.colsurfb.2011.03.041

[26] V. Datsyuk, M. Kalyva, K. Papagelis, J. Parthenios, D. Tasis, A. Siokou, I. Kallitsis and C. Galiotis, "Chemical Oxidation of Multiwalled Carbon Nanotubes," Carbon, Vol. 46, No. 6, 2008, pp. 833-840. doi:10.1016/j.carbon.2008.02.012

[27] P. Hou, C. Liu, Y. Tong, S. Xu, M. Liu and H. Cheng, "Purification of Single-Walled Carbon Nanotubes Synthesized by the Hydrogen Arc-Discharge Method," Journal of Materials Research, Vol. 16, No. 9, 2001, pp. 2526 2529. doi:10.1557/JMR.2001.0346

[28] Y.-H. Wang, C.-M. Chang and Y.-L. Liu, "BenzoxazineFunctionalized Multi-Walled Carbon Nanotubes for Preparation of Electrically-Conductive Polybenzoxazines," Polymer, Vol. 53, No. 1, 2012, pp. 106-112. doi:10.1016/j.polymer.2011.11.040

[29] G. Cavallaro, G. Lazzara and S. Milioto, "Dispersions of Nanoclays of Different Shapes into Aqueous and Solid Biopolymeric Matrices. Extended Physicochemical Study," Langmuir, Vol. 27, No. 3, 2011, pp. 1158-1167. doi:10.1021/1a103487a

[30] G. Cavallaro, D. I. Donato, G. Lazzara and S. Milioto Films of Halloysite Nanotubes, "Sandwiched between Two Layers of Biopolymer: From the Morphology to the Dielectric, Thermal, Transparency, and Wettability Properties," The Journal of Physical Chemistry C, Vol. 115, No. 42, 2011, pp. 20491-20498. doi:10.1021/jp207261r 